ఠ

\title{
Anemia and health performance score evaluation as decisive factors for noninvasive mechanical ventilation decisions in AECOPD: are there new key cornerstones?
}

\author{
This article was published in the following Dove Press journal: \\ International Journal of COPD \\ 30 January 2014 \\ Number of times this article has been viewed
}

\author{
Antonio M Esquinas' \\ Marco Confalonieri ${ }^{2}$ \\ 'Intensive Care Unit, Hospital Morales \\ Meseguer, Murcia, Spain; ${ }^{2}$ Department \\ of Pneumology, University Hospital \\ of Trieste, Trieste, Italy
}

\section{Dear editor}

Determination of prognosis of exacerbation of chronic obstructive pulmonary disease (AECOPD) is a key cornerstone for health cost, organization, systems, and influences determinations of rationale in the use of non-invasive ventilation (NIV). ${ }^{1}$ However, systemic complexity of AECOPD makes it difficult to establish a "gold and perfect" prognosis model. ${ }^{1}$ Recently, a growing number of biological parameters such as anemia and health performance score evaluations are becoming decisive factors for NIV decisions. ${ }^{2}$

In an interesting study, Haja Mydin et al determined that anemia, and performance status based on World Health Organization performance status (WHO-PS) were independent prognostic markers in acute hypercapnic respiratory failure (AHRF) due to AECOPD. ${ }^{3}$ The authors considered the major findings were that WHO-PS $>3$, and anemia, were the best prognostic factors to identify patients unlikely to benefit from NIV.

We believe that the study makes a useful contribution to the establishment of predictors of poor prognosis in patients with AECOPD and it may help to make appropriate decisions for rational use of NIV. However, there are some concerns related to this study.

Firstly, the mechanism of anemia in chronic obstructive pulmonary disease (COPD) and its impact on survival are still unclear; principally it may be associated with acute systemic inflammation in COPD. Nevertheless, anemia prevalence shows a wide range among studies (7.5\%-34\%) and many confounding factors associated to comorbidities may exist. ${ }^{4,5}$ Particularly, the major prevalence of women in this study as sex-factor, could be a conditioning factor. Furthermore, the study did not specify if anemia was associated with hospital readmission. ${ }^{5}$

Secondly, a high frequency of hospital admissions for AECOPD had no prognostic significance in this study, but it was not clarified if previous episodes needed NIV or endotracheal intubation. ${ }^{6}$ Previous reports show that the use of NIV during AECOPD may improve long-term outcomes, in comparison with traditional therapy, including endotracheal intubation. ${ }^{5,6}$

Thirdly, the authors consider that the APACHE II score ${ }^{7}$ is rarely used outside of the intensive care unit (ICU), in favor of more simple parameters. We do not
Correspondence: Anotonio M Esquinas Intensive Care Unit, Hospital Morales Meseguer, Avenida Marques de Los Velez s/n, Murcia, 30.008, Spain

Email antmesquinas@gmail.com 
agree with this interpretation, and believe it deserves some consideration as other studies have demonstrated the usefulness of the APACHE II score ${ }^{7}$ as a solid independent predictor of hospital mortality on multiple regression analysis studies, and a marker for NIV response and health organization in AECOPD, and at large. To our knowledge there are no studies showing that it is not useful in assessing prognosis.

Low performance status is an established prognostic factor for poor outcomes for patients with AECOPD, but this information was well known before the widespread use of NIV in general hospitals. ${ }^{8}$

Finally, the patient population included in this study may be too low with not enough representation to perform a suitable search for independent prognostic markers of a varied clinical condition such as AECOPD. A previous study ${ }^{9}$ recruited a larger number of patients with a wider spectrum of severity eg, 1,033 consecutive patients in the multicenter Confalonieri et al study. Moreover, it was noted that the mortality rate was very high $(33.8 \%)$, in comparison with the majority of randomized clinical trials on NIV in patients with acute hypercapnic failure due to COPD exacerbation, and even more than past studies including ICU patients before the NIV era. ${ }^{5,9}$

In conclusion, we agree that anemia and a low performance status could have a negative impact on the outcome of patients with AECOPD, but possible patient selection bias and the lack of a control group make the interpretation of the results less firm for Haja Mydin et al, ${ }^{3}$ with regards to the decision to use or not use NIV for ventilatory treatment.

\section{Disclosure}

The authors report no conflicts of interest in this communication.

\section{References}

1. Bahadori K, FitzGerald JM. Risk factors of hospitalization and readmission of patients with COPD exacerbation - systematic review. Int J Chron Obstruct Pulmon Dis. 2007;2(3):241-251.

2. Similowski T, Agustí A, MacNee W, Schönhofer B. The potential impact of anaemia of chronic disease in COPD. Eur Respir J. 2006;27(2): 390-396.

3. Haja Mydin H, Murphy S, Clague H, Sridharan K, Taylor IK. Anemia and performance status as prognostic markers in acute hypercapnic respiratory failure due to chronic obstructive pulmonary disease. Int $J$ Chron Obstruct Pulmon Dis. 2013;8:151-157.

4. Comeche Casanova L, Echave-Sustaeta JM, et al. [Prevalence of Anaemia Associated With Chronic Obstructive Pulmonary Disease. Study of Associated Variables]. Arch Bronconeumol. 2013;33:166-185. Spanish.

5. Barba R, de Casasola GG, Marco J, Emilio Losa J, Plaza S, Canora J. Zapatero Anemia in chronic obstructive pulmonary disease: a readmission prognosis factor. Curr Med Res Opin. 2012;28(4):617-622.

6. Kaya A, Ciledağ A, Caylı I, Onen ZP, Sen E, Gülbay B. Associated factors with non-invasive mechanical ventilation failure in acute hypercapnic respiratory failure. Tuberk Toraks. 2010;58(2):128-134.

7. Seneff MG, Wagner DP, Wagner RP, Zimmerman JE, Knaus WA. Hospital and 1-year survival of patients admitted to intensive care units with acute exacerbation of chronic obstructive pulmonary disease. JAMA. 1995;274(23):1852-1857.

8. Roberts CM, Lowe D, Bucknall CE, Ryland I, Kelly Y, Pearson MG. Clinical audit indicators of outcome following admission to hospital with acute exacerbation of chronic obstructive pulmonary disease. Thorax. 2002;57(2):137-141.

9. Confalonieri M, Garuti G, Cattaruzza MS, et al. Italian noninvasive positive pressure ventilation (NPPV) study group. A chart of failure risk for noninvasive ventilation in patients with COPD exacerbation. Eur Respir J. 2005;25(2):348-355. 


\section{Authors' reply}

\author{
Helmy Haja Mydin' \\ Stephen Murphy ${ }^{2}$ \\ Howell Clague ${ }^{2}$ \\ Kishore Sridharan ${ }^{2}$ \\ Ian K Taylor ${ }^{2}$
}

'Department of Respiratory Medicine, Aberdeen Royal Infirmary, Aberdeen, United Kingdom; ' 2 Department of Respiratory Medicine, Sunderland Royal Infirmary, Kayll Road, Sunderland, United Kingdom

Correspondence: Helmy Haja Mydin

Department of Respiratory Medicine, Aberdeen

Royal Infirmary, Aberdeen AB25 IYX, UK

Tel +44 I224 559442

Email helmy.hajamydin@nhs.net

\section{Dear editor}

We thank Drs Esquinas and Confalonieri for their response to our article "Anemia and performance status as prognostic markers in acute hypercapnic respiratory failure due to chronic obstructive pulmonary disease".

We agree that the mechanism of anemia in chronic obstructive pulmonary disease (COPD) is still unclear. The aim of our study ${ }^{1}$ was to identify factors associated with inpatient mortality, and although we found a significant association between anemia and mortality, our study was not designed to investigate causation.

As Esquinas and Confalonieri point out the prevalence of anemia in COPD varies markedly between studies. They suggest a number of confounding factors that may limit the interpretation of our findings particularly the prevalence of comorbidity and the relatively high number of female patients in our study. However we found no association between comorbidity (Charlson index) and anemia but the prevalence of anemia varied according to COPD severity (Global initiative for Obstructive Lung Disease [GOLD] stage IV 59\% versus $17.4 \%$ odds ratio [OR] 6.8 [1.72-29.4]). The high number of female patients in the present study reflects the local epidemiology of COPD, but we did not observe a significant association of anemia by sex (female $36 \%$ versus male $51 \%$ OR 1.89 [0.69-5.1]). Similarly regarding the question of hospital readmissions and anemia there was no difference in the number of admissions for COPD in the previous 12 months (anemia 1.7 [2.4] versus 1.0 [1.2] $P=0.2$ ).

Esquinas and Confalonieri draw attention to the lack of an association between the number of previous admissions and mortality in our study but are unclear if these included episodes requiring noninvasive ventilation (NIV) or invasive mechanical ventilation (IMV). In fact $57 \%$ of patients in the present study had previously required NIV for acute hypercapnic respiratory failure (AHRF) on one or more occasions in the preceding 12 months, but these patients were not at increased risk of death in hospital. Contrary to the suggestion that NIV use may improve long-term outcome compared to other interventions it is clear from this study that the prognosis for patients requiring NIV for AHRF is very poor (58.5\% mortality 12 months after admission), an observation supported by others. ${ }^{2}$

We acknowledge the APACHE II score is a valuable predictor of hospital mortality. However, in our experience it is not routinely calculated in the busy general respiratory ward and is rarely used outside the intensive care unit (ICU). Indeed the study referred to by Esquinas and Confalonieri was in patients admitted to ICUs. ${ }^{3}$

We agree that low performance status as a prognostic factor in the outcome of patients with acute exacerbations of COPD was well recognized prior to the widespread use of $\mathrm{NIV}^{4}$ Indeed assessment of performance status has long been integral to "clinical judgment" and is of particular importance when considering invasive interventions and the ceiling of care for patients requiring NIV.

We acknowledge that there are limitations to our single-center study, including the small number of patients. However, all patients admitted with AHRF due to COPD requiring NIV during the study period were included and therefore were representative of the relevant patient population. The relatively high mortality rate in our study compared to clinical trials of NIV is due to patient selection. Clinical trials can be highly selective - for example, the YONIV study ${ }^{5}$ excluded patients with $\mathrm{pH}<7.26$; indeed more than half of our patients would have been excluded from the YONIV study because of severity of acidosis. But, this reflects current practice in the UK where only $5 \%$ of COPD patients with AHRF are admitted to ICU for IMV compared to other European countries where admission to ICU is routine for such patients. ${ }^{6.7}$

\section{Disclosure}

The authors report no conflicts of interest in this communication.

\section{References}

1. Haja Mydin H, Murphy S, Clague H, Sridharan K, Taylor IK. Anemia and performance status as prognostic markers in acute hypercapnic respiratory failure due to chronic obstructive pulmonary disease. Int $J$ Chron Obstruct Pulmon Dis. 2013;8:151-157. 
2. Chu CM, Chan VL, Lin AW, Wong IW, Leung WS, Lai CK. Readmission rates and life threatening events in COPD survivors treated with noninvasive ventilation for acute hypercapnic respiratory failure. Thorax. 2004;59(12):1020-1025.

3. Seneff MG, Wagner DP, Wagner RP, Zimmerman JE, Knaus WA. Hospital and 1-year survival of patients admitted to intensive care units with acute exacerbation of chronic obstructive pulmonary disease. JAMA. 20, 1995;274(23):1852-1857.

4. Roberts CM, Lowe D, Bucknall CE, Ryland I, Kelly Y, Pearson MG. Clinical audit indications of outcome following admission to hospital with acute exacerbation of chronic obstructive pulmonary disease. Thorax. 2002;57:137-141.
5. Plant PK, Owen JL, Elliott MW. Early use of non-invasive ventilation for acute exacerbations of chronic obstructive pulmonary disease on general respiratory wards: a multicentre randomised controlled trial. Lancet. 2000;355(9219):1931-1935.

6. Roberts CM, Stone RA, Buckingham RJ, et al. Acidosis, non-invasive ventilation and mortality in hospitalised COPD exacerbations. Thorax. 2011;66:43-48.

7. Confalonieri M, Garuti G, Cattaruzza MS, et al. Italian noninvasive positive pressure ventilation (NPPV) study group. A chart of failure risk for noninvasive ventilation in patients with COPD exacerbation. Eur Respir J. 2005;25(2):348-355.

\section{Publish your work in this journal}

The International Journal of COPD is an international, peer-reviewed journal of therapeutics and pharmacology focusing on concise rapid reporting of clinical studies and reviews in COPD. Special focus is given to the pathophysiological processes underlying the disease, intervention programs, patient focused education, and self management protocols.

\section{Dovepress}

This journal is indexed on PubMed Central, MedLine and CAS. The manuscript management system is completely online and includes a very quick and fair peer-review system, which is all easy to use. Visit http://www.dovepress.com/testimonials.php to read real quotes from published authors.

Submit your manuscript here: http://www.dovepress.com/international-journal-of-copd-journal 